( $n$ la década de los 60 , unos fuertes movimientos migratorios arrastraron a multitud de españoles hacia tierras germanas en busca de mejores condiciones socioeconómicas. Habida cuenta, de que en aquel entonces aún no eramos "europeos", al menos no en la medida en que lo somos hoy en día, hubo que adaptarse a una serie de directrices que nos marcaba la Alemania de un lenguaje eminentemente científico, si parece ajustarse a este denominado lenguaje teórico, puesto que el ejemplo que propone $v$. Hahn cuando se refiere a "Kraftfahrzeug" (automóvil) en lugar de "Wagen"(coche) hace una clara alusión al lenguaje que está siendo objeto de análisis.

Para aclarar el concepto de "Fachsprachen" es enormemente orientativa la siguiente idea de

\title{
¿LENGUAIE VIAL O/ODER VERIKEHRSSPRACHE?
}

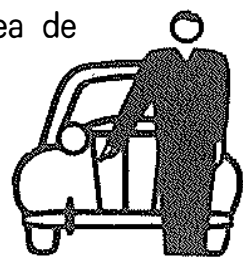

aquella época. Una de las mencionadas directrices se refiere al permiso de conducir (Führerschein). Algunos españoles, en concreto aquellos que, a pesar de que ya obtuvieron el permiso de conducción en su país natal, pero que no poseian vehículo propio y que no podian acreditar su antigüedad como conductores, tuvieron que volver a superar las pruebas pertinentes para adquirir dicho permiso.

Tras recoger los testimonios de un emigrante, cuyo "Führerschein" da fe a sus palabras, además de haberme facilitado algunas de sus notas y apuntes procedentes de la enseñanza recibida en una AutoEscuela de la citada época, presento una breve relación de preguntas de examen. Después de haber realizado las correcciones oportunas y compararlas con preguntas de test actualizadas, todas las que se exponen a continuación, aparecen junto a su respuesta correcta, acompañadas de sus respectivas traducciones.

Este tipo de lenguaje, el lenguaje vial, puede ser englobado en uno de esos campos que abarcan las lenguas especiales (Fachsprachen). Si el lenguaje vial no se ajusta de forma integra a la primera definición de las "Fachsprachen" de v. Hahn1, cuando establece que estas lenguas sirven para la comunicación de sistemas de trabajo en materias técnicas y científicas, si puede ser incluido en el grupo de la "Theoriesprache" o también denominada "Wissenschaftsprache"2. Este lenguaje teórico o científico, que se entiende como la vertiente más estricta de la lenguas especiales se distancia considerablemente del lenguaje coloquial. Aunque el lenguaje vial no es
Fluck, que explica las peculiaridades de los lenguajes especiales:

"Die Besonderheit der Fachsprachen hingegen [...] liegt einmal in ihrem speziellen, auf die Bedürnisse des jeweiligen Faches abgestimmten Wortschatz, dessen Übergänge zur Gemeinsprache fliessend sind und der auch gemeinsprachliche und allgemeinverständliche Wörter enthält. Zum anderen liegt ihre Besonderheit in der Gebrauchsfrequenz bestimmter (gemeinsprachlicher) grammatischer (morphologischer, syntaktischer) Mittel"3.

Por tanto, las "Fachsprachen" se caracterizan por el uso de una terminología específica en las que también hace su aparición un lenguaje coloquial, unido a una sintaxis y morfología adecuadas. Aunque es obvio, que la característica predominante en las lenguas especiales se encuentra en el léxico. Asi, lo corrobora Fluck:

"Zu dem am besten erforschten fachsprachlichen Besonderheiten zählen die verschiedenen lexikalischen Eigenschaften, und nach wie vor kommt der Fachlexik eine zentrale Bedeutung im Hinblick auf die Beschreibung und Bestimmung von Fachsprachen zu"4.

Además de Fluck, Hoffmann también señala el predominio del léxico en las lenguas especiales5.

Tras esta breve consideración acerca de las lenguas especiales pasamos a la parte práctica.

1.E) ¿Cómo se comportará al aproximarse a un 
paso cebra?

Permitir a los peatones que atraviesen la calle, parando si fuese preciso.

1.D) Wie verhalten Sie sich beim Annähern an einen Zebrastreifen?

Den Fussgängern das Überqueren ermöglichen, wenn nötig anhalten.

2.E) En un semáforo está encendida la luz verde. Delante del cruce hay colocada a la derecha una señal de "Ceda el paso". ¿Cómo es preciso comportarse?

Pasar por el cruce sin parar.

2.D) An der Verkehrsampel leuchtet grünes Licht. Vor der Kreuzung steht rechts das Zeichen: "Vorfahrt achten". Wie muss man sich verhalten?

Man überquert die Kreuzung ohne anzuhalten.

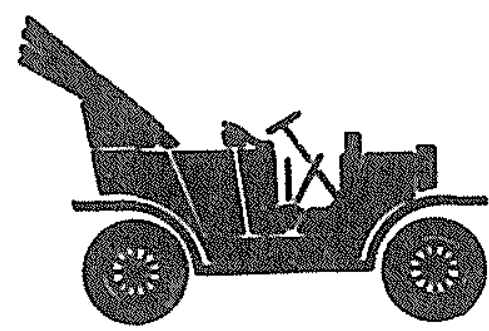

3.E) ¿Cómo deben tomarse las curvas?

Aminorar la velocidad antes de la curva y volver a acelerar dentro de la curva.

3.D) Wie soll man Kurven durchfahren?

Vor der Kurve Geschwindigkeit vermindern, in der Kurve wieder beschleunigen.

4.E) ¿Cómo se comportará si le deslumbran los faros de un vehículo que se acerca en dirección contraria?

Reducir la velocidad y parar si fuese preciso. 4.D) Wie verhält man sich bei Blendung durch entgegenkommende Kraftfahrzeuge? anhalten.

Geschwindigkeit vermindern und wenn nötig

5.E) ¿Qué indica la luz de control azul de un automóvil?

Que está conectada la luz de carretera.

5.D) Was zeigt die blaue Kontrollampe im Kraftwagen an?

Fernlicht ist eingeschaltet.
6.E) Vd. circula de noche con la luz de carretera y le adelanta otro vehículo, que ahora se coloca delante del suyo, ¿tendrá Vd. que poner la luz de cruce?

Es necesario poner la luz de cruce.

6.D) Sie fahren nachts mit Fernlicht und werden von einem Fahrzeug überholt, das jetzt vor Ihnen fährt. Müssen Sie abblenden?

Abblenden ist notwendig.

7.E) ¿Cuál es la regla fundamental, que regula la

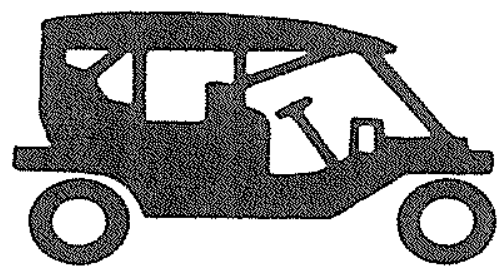

preferencia de paso en los cruces?

La derecha tiene preferencia con respecto a la izquierda.

7.D) Welche Hauptregel für die Vorfahrt gilt an Kreuzungen?

Rechts vor links.

8.E) Vd. llega a un cruce y se da cuenta de que otro automovilista no respeta su preferencia de paso,

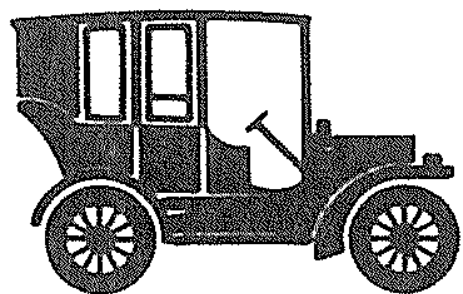

¿comó se comportará para evitar un accidente?

Renunciar a la preferencia de paso.

8.D) Sie kommen an eine Kreuzung und erkennen, dass ein anderer Autofahrer die Vorfahrt nicht beachtet. Wie verhalten Sie sich, um einen Unfall zu vermeiden?

Auf die Vorfahrt verzichten.

9.E) En el centro de la calzada hay dibujada una línea blanca continua. ¿Qué debe tenerse en cuenta si se quiere adelantar aquí?

Está prohibido cruzar la línea divisoria.

9.D) Auf der Fahrbahnmitte ist eine weisse, nicht 


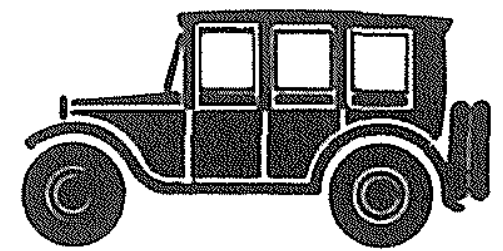

unterbrochene Linie aufgezeichnet. Was ist an dieser Stelle beim Überholen zu beachten?

Die Begrenzungslinie darf man nicht überfahren.

10.E) ¿Está permitido cruzar la línea blanca discontinua en el centro de la calzada?

$\mathrm{Si}$, siempre que no se ponga en peligro a los demás conductores.

10.D) Darf eine unterbrochene weisse Mittellinie überfahren werden?

Wenn der übrige Verkehr dadurch nicht gefährdet wird.

11.E) ¿Cuándo se tiene derecho a cruzar un paso a nivel?

Después de haber comprobado que no viene ningún tren.

11.D) Wann darf ein Bahnübergang überquert werden? kommt.

Wenn man sich überzeugt hat, dass kein Zug

12.E) ¿Qué significa la luz verde de un semáforo?

Paso libre en cualquier dirección.

12.D) Was bedeutet das grüne Licht an einer Verkehrsampel?

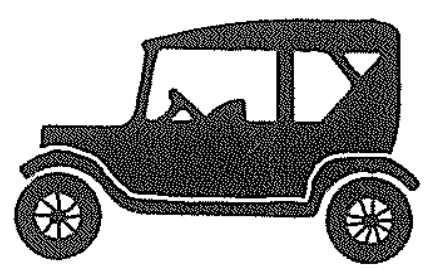

Freie Fahrt nach allen Richtungen.

13.E) ¿Dónde es preciso colocarse en una calle de dirección única para girar a la izquierda?

Lo más a la izquierda posible, pasado el cen- tro de la calzada.

13.D) Wo ordnet man sich beim Linkseinbiegen auf einer Einbahnstrasse ein?

Möglichst weit links über die Fahrbahnmitte hinaus.

14.E) Por descuido pasa de largo la salida de la autopista, por la que tenia previsto salir. ¿Cómo se comportará?

Seguirá hasta la próxima salida.

14.D) Sie sind an der Ausfahrt der Autobahn, an der Sie ausfahren wollten, versehentlich vorbeigefahren. Wie verhalten Sie sich?

Sie fahren bis zur nächsten Ausfahrt weiter.

15.E) En una calle de dirección única no hay colocada ninguna señal que prohiba aparcar. ¿Dónde está permitido aparcar?

A la derecha y/o a la izquierda.

15.D) In einer Einbahnstrasse ist kein Parkverbotszeichen aufgestellt. Wo darf man parken?

Rechts und/oder links.

16.E) ¿Cómo debe comportarse si no le queda tiempo para terminar la maniobra de adelantamiento? Interrumpir el adelantamiento.

16.D) Wie verhalten Sie sich, wenn der Überholvorgang nicht rechtzeitig beendet werden kann?

Überholvorgang abbrechen.

17.E) Le está permitido seguir utilizando su automóvil si ha caducado el seguro de responsabilidad civil?

No está permitido.

17.D) Dürfen Sie Ihr Kraftfahrzeug weiterbenutzen, wenn die Haftpflichtversicherung die Gültigkeit verloren hat?

Weiterbenutzung ist nicht zulässig.

18.E) ¿Tiene que poner la luz de cruce si se acerca un ciclista en dirección contraria?

Es necesario poner la luz de cruce.

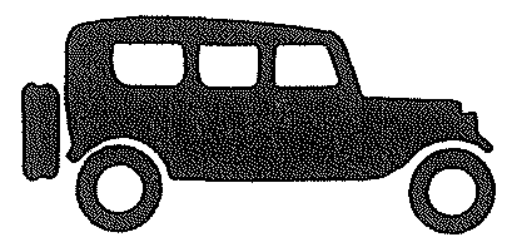


\&(0)

\section{Sprechen Sie Deutsch?}

\section{GOETHE INSTITUT}
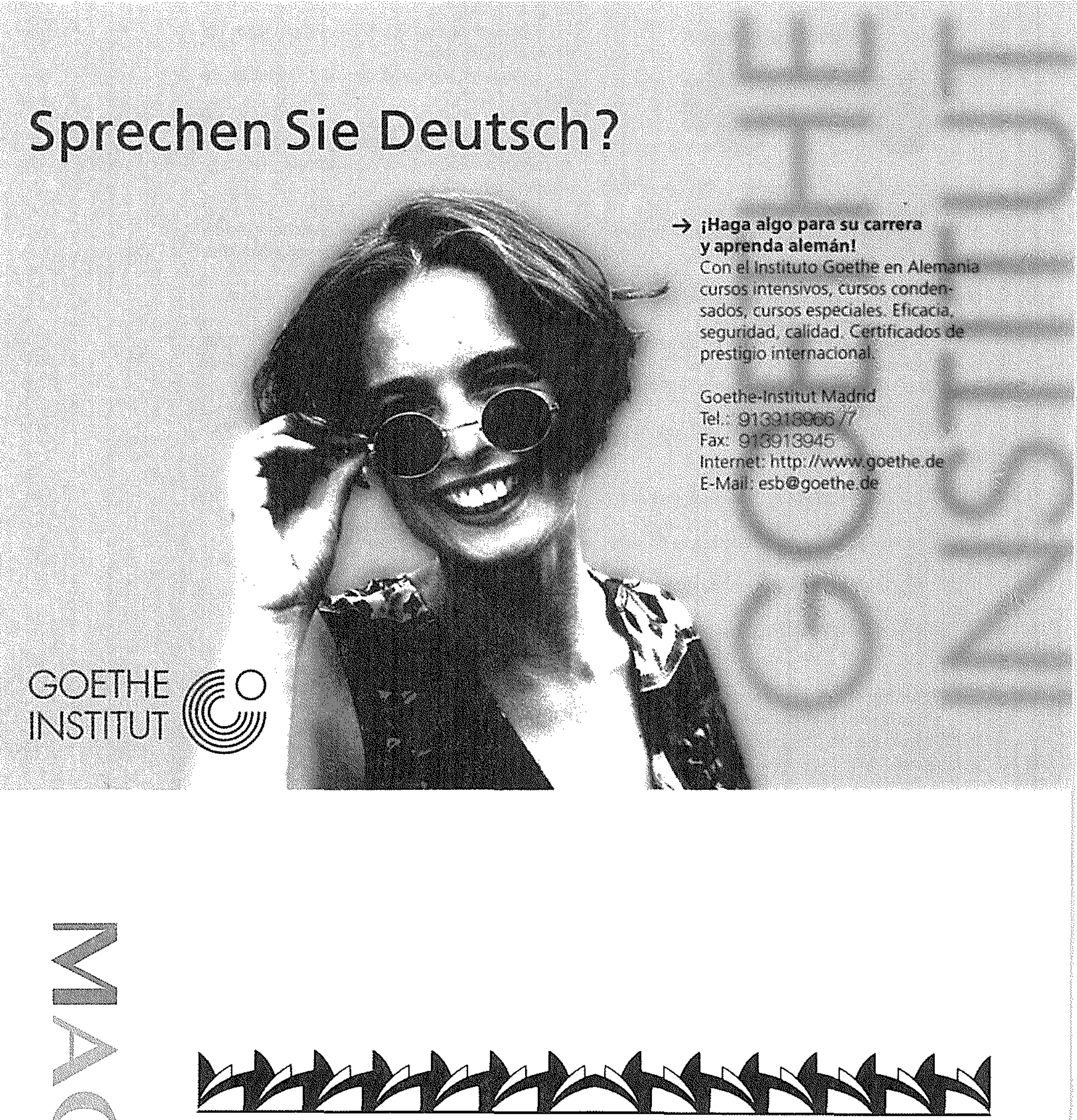

(

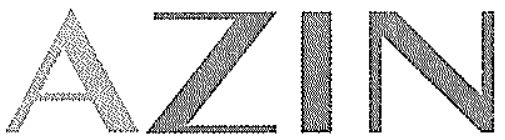


18.D) Müssen Sie abblenden, wenn ein Radfahrer entgegenkommt?

Abblenden ist notwendig.

19.E) ¿En qué caso es preciso poner la luz intermitente?

Antes de girar a un lado.

19.D) In welchen Fall muss der Blinker eingeschaltet werden?

Vor dem Einbiegen.
20.E) ¿Comó se comporta cuando le adelanta otro automóvil?

Circular lo más a la derecha posible y no aumentar la velocidad.

20.D) Wie verhält man sich, wenn man überholt wird?

Möglichst weit rechts fahren und Geschwindigkeit nicht erhöhen.

A.C.S.

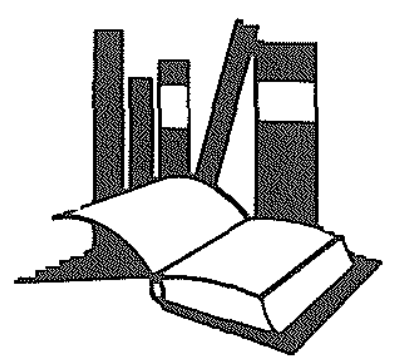

BIBLIOGRAFÍA:

- Fluck, H.-R., Fachsprachen, München, Francke Verlag, 1976.

- Hahn, W. von, "Fachsprachen". En: Althaus, H.P./ Henne, H./ Wiegand, H.E. (eds.), Lexikon der Germanistischen Linguistik, Tübingen, Niemeyer Verlag, 1980 ( $2^{3}$ ed.), págs. 390-395.

- Hoffmann, L., "Gemeinsamkeiten und Unterschiede in den Fachsprachen". En: Zeitschrift

\section{NOTAS}

1 Vid. W. von Hahn, "Fachsprachen", en H.P. Althaus/H. Henne/H. E.Wiegand (eds.): Lexikon der germanisti schen Linguistik, Tübingen, Niemeyer Verlag, 1980, pág.390.

2 Ibidem, pág. 391.

3 H.-R., Fachsprachen, München, Francke Verlag, 1976, pág.12.

4 lbidem, pág.201.

5 Vid. L. Hoffmann, "Gemeinsamkeiten und Unterschiede in den Fachsprachen". en Zeitschrift für Gemanistik 4 (1986), pág. 460.

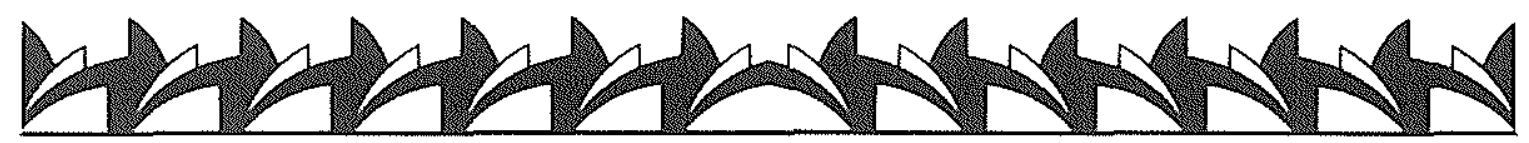

